\title{
Tissue Culture of Retinal Glial Cells
}

\author{
F J SAVAGE, J E DAY, P HOGG and I GRIERSON \\ London
}

\section{SUMMARY}

In order to be able to investigate the properties and characteristics of glia in the retina, a monotypic culture of retinal glial cells is likely to be an important research vehicle. Several techniques are now available to produce cultures of glial cells from the retina. These methods generally result in cultures of Mueller cells rather than retinal astrocytes. Publications on glial cultures involved complex procedures for the isolation of the target cell. Recent developments have resulted in simpler procedures with the advantage that large numbers of cultures can be established quickly and easily. Glial cultures have already been used in a variety of studies, simpler methods of culture, particularly if these can be adapted for culture of human glial cells, will probably result in more extensive use of cultures to unravel the properties of retinal glia.

Glial cells are the support and nutritive cells for neurons in the retina, being essential for survival of the neurons. Interactions between glia and neurons are thought to play an important role in processing of information and in the maintenance of a balance of ions, transmitters and metabolites, to provide an optimal environment for neuronal activity. ${ }^{1,2}$ To determine the characteristics and behaviour of glial cells and to ascertain how they function to maintain a consistent environment, requires a pure cell population. This necessitates the isolation of cells from the retina and their maintenance in culture. Cultures can then be used to investigate the normal behaviour of cells and also the effect of adding specific substances to the culture, for example to assess toxicity or antiproliferative ability of drugs.

Glial cells were first cultured from the brain, however its glial composition is different to the eye so that these cultures may not be appropriate for ocular studies. ${ }^{3}$ Glial cultures from the retina were derived initially from embryonic tissue. ${ }^{4}$ The cells surviving in cultures from embryonic tissue may be stem cells and these may not exhibit the same properties as differentiated glial cells.
Study of Mueller cells was hampered by the difficulty in growing them in vitro from their differentiated state in the mature retina. Initially, glia were isolated from the retina but were not cultured and the cells only survived a few hours. ${ }^{5,6}$ The technique was modified so that the isolated cells grew in culture, ${ }^{7,8}$ however the procedure was complex and time-consuming. A simpler technique for obtaining cultures of retinal glial cells from the rabbit retina was developed by Burke and Foster. ${ }^{9}$ However the rabbit has a predominantly non-vascular retina which may not be appropriate for studies relating to human pathological conditions.

The development of a simple method to obtain large numbers of glial cells from a vascular, adult retina will allow examination of aspects of Mueller cell physiology and pathology.

\section{Anatomy}

There are several types of neuroglial cells including astrocytes, oligodendrocytes, perivascular glia and Mueller cells having different functions and, in some species, different locations within the retina. 


\section{Vascular Retina}

The vascular retina (e.g. human, monkey, rat etc) contains several types of glial cells of which the Mueller glia form the largest volume with astrocytes, microglia and perivascular glia also being present.

Mueller glia arise from the retinal neuroepithelia. The cells have a nutritive and a supportive role for the neurons. One of their most important functions is to provide glucose to the nerve cells and they can synthesise and store glycogen. ${ }^{10,11}$ Mueller cells are elongated with their nucleus located in the middle portion of the inner nuclear layer, and the cytoplasm expands radially the whole width of the retina from the outer limiting membrane to the inner limiting membrane. As it passes through the different layers, the Mueller cell is alongside all of the neurons within the retina. The inner limiting membrane of the neural retina is formed by the overlapping of the endfeet of Mueller cells and the outer limiting membrane occurs at the junction of the Mueller cells and photoreceptors. The processes of the cells enclose the neurons, insulating the nerve fibres and filling in much of the space. In retinal layers that contain blood vessels Mueller cell processes surround large areas of the capillaries and some of the surfaces of the larger vessels. ${ }^{10,12}$ The close contact of Mueller cells with the other retinal cells ensures that there is little extracellular space in the retina.

Microglia are found in the inner retina, especially in the nerve fibre layer. ${ }^{10}$ There are normally very few of these phagocytic cells and they are the retinal equivalent of the fixed histiocyte or macrophage present in connective tissue. They are difficult to identify in normal tissue becoming apparent only when they have ingested material. It is thought that most of the macrophage cells observed in pathological tissue originate from the blood stream. ${ }^{12}$

The origin of astrocytes in the retina has been the subject of debate. It has been suggested that, in common with Mueller cells, they arise from retinal neuroepithelial cells. Another proposal has been that they migrate from the optic nerve. Evidence for the latter has been provided by Watanabe and Raff ${ }^{13}$ who have shown that there is migration of astrocytes from the optic nerve into the retina during embryonic development of the rat.

To be able to visualise glial cells in the retina it is necessary to employ silver stains, ${ }^{14}$ with this technique Wolter ${ }^{15}$ was able to distinguish astrocytes in the nerve fibre, ganglion cell and the inner and outer plexiform layers. There are two types of astrocytes, elongate and stellate. ${ }^{16}$ Elongate astrocytes have long processes which run parallel to the nerve fibre bundles and do not make any vascular connections. Stellate astrocytes have shorter processes which cross the nerve fibre bundles enclosing a circular area. These cells do have vascular attachments but they are not specialised like those of astrocytes in the central nerve system. ${ }^{16}$ The astrocyte density is highest at the optic nerve extending across the temporal retina above and below the area centralis corresponding to the position of the arcuate nerve fibres with the density rapidly decreasing away from this area. ${ }^{16}$

Perivascular glia are easily visualised using silver staining ${ }^{17}$ and are seen to be associated with blood vessels, lying outside the capillaries whereas the pericytes lie within. The cell body is star-shaped and has many long processes that wind round the walls of the blood vessels. ${ }^{12}$

\section{Avascular Retina}

In the avascular retina (e.g. rabbit, guinea pig) oligodendrocytes and astrocytes only occur in the medullary ray, the region formed by myelinated optic nerve fibres. The astrocytes establish contacts with blood vessels located within the medullary ray, usually via an extended process, their perikarya being situated at some distance from the vessel. Astrocytes have also been shown to be in contact with blood vessels in human, ${ }^{17}$ rat $^{18}$ and mouse ${ }^{19}$ retinae. Astrocyte processes are aligned parallel to the ganglion cell axons and may be necessary for maintenance of the axons.

The distribution of glial cells in the rabbit retina was found to be related partly to the thickness of the nerve fibre layer and partly to total retina thickness. ${ }^{20}$ The density of the Mueller cells increased as the retina became thicker. In the centre of the retina, near the optic disc, where the retina was at its thickest due to the bulge of the nerve fibre layer the vitreal processes of several Mueller cells ran together through the nerve fibre layer bypassing large bundles of optic axons. It was in this region that the non-radial glial cells, the astrocytes and oligodendrocytes, occurred. In the rabbit, the glia:neuron ratio remained constant except very close to the optic nerve, where it was 
increased due to the presence of astrocytes. Astrocytes were only found where the nerve fibre layer was greater than $130 \mu \mathrm{m}$, however this did not apply in other species, where overall retinal thickness was more closely related to the presence of astrocytes than that of the nerve fibre layer. The blood vessels appeared to have the most influence on the distribution of astrocytes because they were absent from areas of the retina lacking vessels as was seen in the rabbit and the horse which have predominantly avascular retinae. ${ }^{21}$ In the vascular retina of the monkey astrocytes are not present in a small area, surrounding the fovea centralis, which also lacks blood vessels. ${ }^{21}$

In the rabbit retina, Mueller cells represented $7 \%$ of the total retinal cell number and occupied $6.8 \%$ of the retinal volume. ${ }^{22}$ In the outer nuclear layer there was one neuron per Mueller cell whereas in the inner nuclear layer there were two neurons. ${ }^{22}$ The morphology of the Mueller cell was dependent on its location in the retina, at the periphery of the retina the cells were short and characterised by a thick vitreal process bearing a single endfoot, towards the centre of the retina the processes became thinner and the endfoot smaller. ${ }^{20}$ As the nerve fibre layer thickened the vitreal processes of Mueller cells divided into several fine branches each bearing a very small endfoot. Immediately adjacent to the optic nerve region, in the thickest region of both the retina and the nerve fibre layer, Mueller cell morphology again became rather simple, being characterised by a very long and thin vitreal process, having one or occasionally several endfeet. ${ }^{20}$

Magalhaes, ${ }^{23}$ looked at whether different areas of the Mueller cell were specialised for differing functions. One of the major functions of these cells is glucose synthesis and this predominantly occurred in the inner cell portion which contained a dense network of smooth cisternae being the site of glucose-6-phosphatase activity, using glycogen as a source of glucose. Glycogen was stored, in a beta form, as single particles in the cytoplasm of the Mueller cells. ${ }^{11}$ Although glycogen was evenly distributed throughout the cytoplasm, this still resulted in a retinal glycogen gradient because the inner retina contained more extensive areas of cytoplasm and consequently more glycogen. The glycogen is required for anaerobic glycolysis so that an even supply of energy to the inner retina is maintained in the absence of a vascular supply. ${ }^{24}$ The middle portion of the Mueller cell was rich in free ribosomes, rough endoplasmic reticulum cisternae and Golgi complex and this was the site of protein synthesis. ${ }^{23}$ The outer portion was adapted for absorption and intracellular transport with its numerous microvilli and microtubules. ${ }^{23}$

\section{Techniques of Culturing}

Some of the first cultures to be reported were from embryonic tissue, in particular from the chick retina. Adler et $\mathrm{al}^{4}$ using embryonic chick neural retina, showed that the type of cell that was produced was dependent on the conditions of the culture. When a low adhesive substrata was used, the explanted cells formed clumps. If fetal calf serum was a component of the culture medium, flat cells (presumed to be glia) spread throughout the culture flask. However if horse serum served as the medium supplement, the glial cells remained in clumps. The use of glial highly adhesive substrata gave clump-free, flat cell-free, pure retinal neuronal cultures.

The first method to be published for the isolation of glial cells from adult tissue was by Sarthy and Lam in 1978..$^{5}$ They used the turtle retina because it contained Mueller cells which were much larger than the neurons so that two cell types could be readily separated by velocity centrifugation and visual isolation to obtain a homogeneous cell population. Retinae were incubated for two hours in an isotonic calciumfree Ringer's solution containing papain and EGTA. The retinae were placed in normal Ringer's containing bovine serum albumin and deoxyribonuclease and the retina dissociated by pipetting the tissue gently up and down with a pasteur pipette. The suspension was allowed to settle and the supernatant removed and the process repeated until there was no undissociated retinal tissue. The preparation usually produced four fractions and the one containing the most Mueller cells as observed by Nomarski optics was further purified. The fraction was applied to a bovine serum albumin or Percoll gradient and velocity sedimentation carried out at $\mathrm{lg}$ for four hours and the various fractions eluted and the number and type of cells in each one determined. The fractions containing Mueller cells were spread on glass slides and individual cells selected under Nomarski optics. Characteristics associated with Mueller cells 
were present including glutamine synthetase and carbonic anhydrase activities as shown by the increase in their specific activity compared to retina and dissociated retinal cells.

Roberge et $\mathrm{al}^{7}$ isolated glial cells from the adult rat retina using the Trachtenberg and Packey modification $^{6}$ of Sarthy's technique in which an amphoteric buffer was utilised allowing the bicarbonate to be reduced to prevent swelling of glial cells. The velocity sedimentation procedure was replaced by gradient centrifugation. The isolated cells were cultured by placing them in minimal essential media (MEM) supplemented with $10 \%$ fetal calf serum (FCS), HEPES $25 \mathrm{mM}$ $100 \mathrm{U} / \mathrm{ml}$ penicillin, $100 \mu \mathrm{g} / \mathrm{ml}$ streptomycin, $50 \mu \mathrm{g} / \mathrm{ml}$ gentamicin, $2 \mathrm{mM} \mathrm{L}$-glutamine and $20 \%$ $\mathrm{v} / \mathrm{v}$ of Concanavilin A spleen cell conditioned medium. Cells placed in media with FCS but no conditioned media remained stable, non-confluent and did not proliferate, such cultures could be maintained for four months consisting of a static population of large, flat and irregularly shaped cells. Cultures supplemented with spleen conditioned media proliferated with doubling time of approximately four days. These cells were smaller and thicker in appearance their shape being dependent on the stage in the cell cycle and the proximity of the culture to confluence. Dividing cells were phase bright and initially they became polygonal epithelioid in shape and later stellate while densely packed cultures took on a fibrous appearance. Cultures could be passaged and maintained to at least 13 passages. Transmission electron microscopy showed the presence of cytoplasm with abundant ribosomes, glycogen granules, smooth endoplasmic reticulum and intermediate filaments. The cultures were characterised using antisera against glial fibrillary acidic protein (GFAP) and a monoclonal antibody to Mueller cells developed in their laboratory. ${ }^{25}$

Sarthy ${ }^{8}$ also cultured glia from adult rat retina but he used retinae in which there was photoreceptor degeneration produced either by exposure to constant light or by a genetic defect. Cells were isolated from these degenerated retinae by trypsin treatment, with clumps of cells being dispersed by vigorous trituration and the resultant single cells were plated into dishes. Initially the cells were elongated with a spiky morphology and then became flattened as they proliferated. Addition of conditioned medium was found not to be required and good growth took place in it's absence. Cultures became confluent and in this state were maintained for 4-6 weeks. The cells were thought to be glia because most stained with anti-GFAP. Neurons, a possible contaminant of the culture, were not present because the cells were not stained by an antibody to tetanus toxin. It was concluded that the cells were predominantly Mueller cells since monoclonal antibodies against glutamine synthetase and carbonic anhydrase were positive. The isolation procedures produced Mueller cell cultures but the technique was complicated and compromised viability because the cells could be maintained for only a limited period. Thus the procedure was impractical as a way of producing the large numbers of cells needed for most experimental studies.

Burke and Foster ${ }^{9}$ developed a much easier method for the culture of glial cells from the rabbit retina. Isolation of the Mueller cells before culture was shown to be unnecessary. The rabbit optic nerve is surrounded by superficial myelinated nerve fibres which form the medullary rays. Blood vessels are restricted to the medullary rays and vascular elements from this tissue grow readily in culture. Fortunately this tissue can be easily isolated from the retina. Burke and Foster removed the retina, discarded the medullary rays and washed the retinal explant in serum-free MEM to remove adherent retinal pigment epithelia. The explant was cut into small pieces and suspended in $20 \mathrm{ml}$ medium containing $10 \%$ fetal bovine serum (FBS) and antibiotics, and cultured in flasks under $5 \% \mathrm{CO}_{2}$. After ten to 14 days in culture the medium containing the tissue was removed and centrifuged. The pelleted tissue was resuspended in fresh medium and replaced in the culture flask, within one or two days the tissue adhered and there was rapid proliferation of the cells, which could then be passaged by trypsin treatment. The cells grown by this method were phenotypically diverse. Epithelioid, fibroblastic, stellate and large flat plate-like forms were recognised. Many of the cells in primary culture were bi- or multinucleate. On passaging, the cells developed a more homogeneous appearance being predominantly epithelioid. The cells were thought to be Mueller glia because

(a) astrocytes and oligodendrocytes are restricted to the medullary ray which had been removed, 
(b) neural cells do not grow in the culture conditions provided

(c) autoradiography of the necrosing retina showed these were the only cells to be undergoing DNA synthesis.

However the cells could not be stained with antibodies to the glial markers GFAP or glutamine synthetase. Growth rate was highest in early cultures as shown by the time taken to reach confluence and DNA synthesis was highest in primary and first passage cultures. Cell number per flask was maximal at first passage because at higher passage cells were larger and flatter. In cultures above first passage, it appeared that very few of the cells were capable of proliferating and after fourth passage confluence could not be established.

There are limitations with all the current techniques available for the culture of glial cells from the retina. The methods of Sarthy ${ }^{8}$ and Roberge et $\mathrm{al}^{7}$ are impractical for the preparation of large numbers of cultures which may be necessary for some experimental work. The requirement of spleen conditioned media for growth ${ }^{7}$ may result in cells having atypical properties. Although culture of glial cells from the rabbit retina is an easy technique, these cultures do not grow rapidly, confluence cannot be obtained after fourth passage and the use of an avascular retina may not be appropriate for some studies. There is therefore a need for a simple method of culture of glial cells from a vascular retina. We have investigated two methods of glial culture using the bovine retina. Retina was removed from a bovine eye which had been left at $4^{\circ} \mathrm{C}$ for 24 hours, and washed in three changes of phosphate buffered saline (PBS), to remove adherent retinal pigment epithelial cells. Small pieces of retina, approximately $1 \mathrm{~cm}^{2}$, were floated in $25 \mathrm{~cm}^{2}$ flasks containing $15 \mathrm{ml}$ minimal essential media with Earle's salts (Gibco), $15 \%$ newborn calf serum (NCS, Gibco), penicillin and streptomycin (100 units/ml, Gibco) and amphotericin B (0.25 units $/ \mathrm{ml}$, Flow). They were incubated at $37^{\circ} \mathrm{C}$ and $5 \% \mathrm{CO}_{2}$ and the appearance of cells monitored by phase contrast microscopy.

The major problem associated with glial culture from vascular retinae is possible contamination by blood vessel cells such as pericytes, smooth muscle cells and endothelium. In the other technique, blood vessel fragments were removed. After washing the retina, it was homogenised with a glass-teflon PotterElvehjem homogeniser and the homogenate was spun at $1600 \mathrm{rpm}$ for 10 minutes, the supernatant was discarded and the pellet resuspended in serum-free media. The suspension was passed through an $85 \mu \mathrm{m}$ mesh (Henry Simon Ltd, Stockport, Cheshire) and the filtered solution was spun at $1,000 \mathrm{rpm}$ for 10 minutes. The cell pellet was resuspended in MEM and passed through a $53 \mu \mathrm{m}$ mesh (Henry Simon Ltd). The suspension of disassociated cells was divided between $25 \mathrm{~cm}^{2}$ flasks into which $1 \mathrm{ml}$ of NCS had been placed and $3 \mathrm{ml}$ of MEM containing $15 \%$ NCS was added. The cells were incubated at $37^{\circ} \mathrm{C}$ in $5 \% \mathrm{CO}_{2}$. The appearance of the cells was monitored by phase contrast microscopy.

Once cells had settled and spread, the NCS was replaced with $10 \%$ FCS and the cultures were fed twice a week with $5 \mathrm{ml}$ of MEM containing FCS. Cultures isolated by both methods became confluent in three to four weeks and then were passaged, using a trypsin/EDTA solution $(0.25 \%$ trypsin and $0.02 \%$ EDTA) although, in common with rabbit cultures, ${ }^{9}$ the cells were difficult to remove from the flask, suggesting strong cell adhesion. Cells could be passaged to at least tenth passage. From pieces of floating tissue, cells were seen to drop out and settle after seven days in culture. Initially the cells were round with ruffled membranes and microspikes (Fig $1 \mathrm{~A}$ and $\mathrm{B}$ ). As the cultures became more confluent, after 14 to 21 days, the cells became elongated and flattened (Fig 2A). At confluence the cells had a reduced surface area when compared to the large preconfluent cells (Fig 2B). Contact inhibition did not occur, the cells overlapped each other. Postconfluent cells were seen to retract to form mounds of cells from which new cells grew to recolonise the area of flask left vacant (Fig 3).

Autoradiography, using ${ }^{3} \mathrm{H}$-thymidine, of the floating tissue at different times after placing the tissue in culture showed no evidence of cells undergoing DNA synthesis until the seventh day in culture. At seven days large round cells were present in the degenerating retina. The round cells were healthy and were the only cells to incorporate thymidine (Fig 4A). The labelling of these cells increased with time in culture from $35 \%$ at one week to $46 \%$ at two weeks and $60 \%$ at three weeks. We considered that the round cells involved in DNA synthesis were Mueller cells because they were larger than astrocytes and demonstrated 

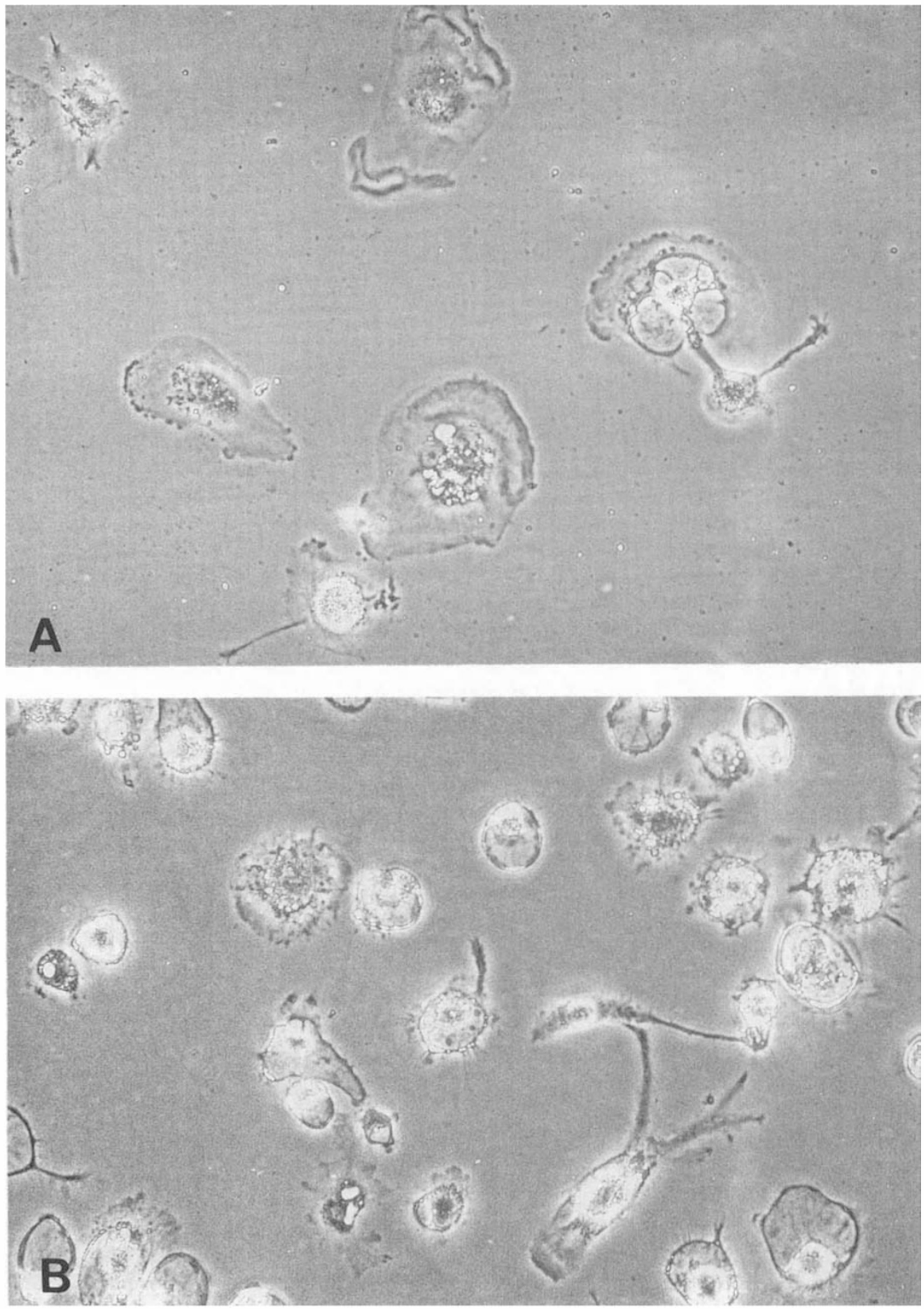

Fig. 1. Settlement in primary culture prior to growth using $(A)$ the mesh procedure and $(B)$ the float technique. (phase contrast (A) $400 \times(B) 300 \times)$. 



Fig. 2. (A) Preconfluent retinal glia at first passage. The cells are flattened and elongated.

(B) Confluent retinal glia at third passage. At confluence the cells are smaller and show some overlapping. (phase contrast $(A) \times 200$ (B) $\times 200$ ). 


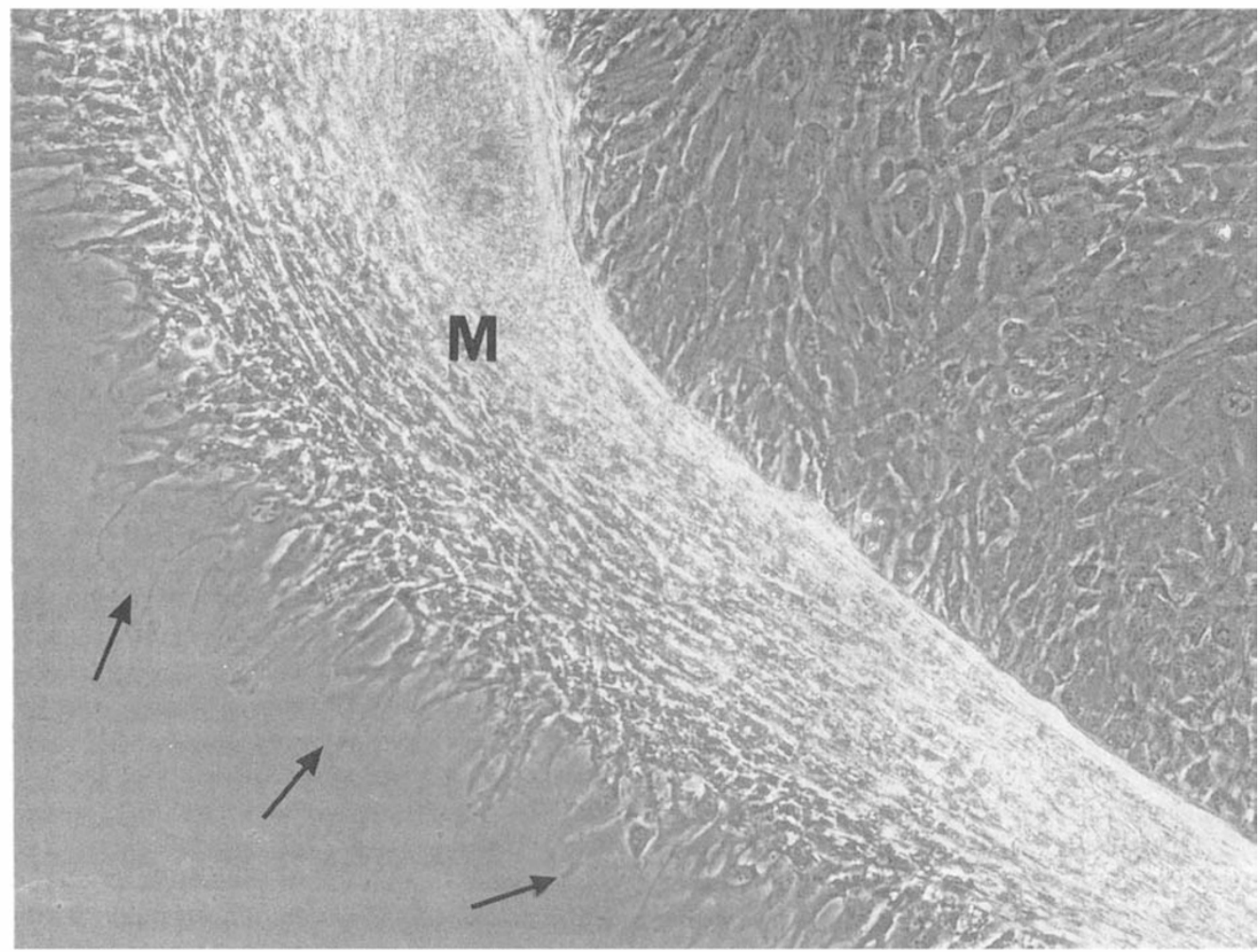

Fig. 3. Primary culture which is approximately one week post-confluent, shows areas where the monolayer has retracted (like a rolled u carpet) to form a mound $(M)$ leaving a bare region on the flask where regrowth can take place (arrows). (phase contrast $\times 200)$.

positive GFAP staining in their cytoplasm. At no time were any of the blood vessel cells seen to be undergoing DNA synthesis (Fig 4B).

Cells isolated via meshes settled between the first and the fourth day in culture. The appearance and behaviour of the cells was the same as for those isolated from floating tissue.

Growth curves were established on first to fifth passage cultures by seeding $7.52 \times 10^{3}$ cells per $\mathrm{cm}^{2}$. The number of cells were counted until confluence was reached at approximately two million cells per flask. It was obvious that higher passage cells reached confluence more quickly than lower passage cells (Fig 5). First passage cells only reaching confluence on the sixteenth day in culture compared to second passage cells becoming confluent by the thirteenth day and third passage cells by the eighth day. The cells isolated by both methods demonstrated carbonic anhydrase and glutamine synthetase activities. Carbonic anhydrase activity was shown in cultures using a histochemical reaction. ${ }^{26}$ Glutamine synthetase activity could be measured in post-confluent cultures after induction with hydrocortisone (1.5 $\mathrm{mM}$, for 48 hours), an activity of $9.88 \pm 3.12$ $\mu \mathrm{M} / \mathrm{min} / 10^{6}$ cells was determined.

GFAP is a marker for astrocytes and in some circumstances can be demonstrated in Mueller cells. Monoclonal antibodies against GFAP did not stain the cultured cells, however an antiserum against GFAP (gift from Dr U Chakravarthy, ${ }^{27}$ ) did stain our cells. S-100, is a protein located in glial cells in the central nervous system and retina. Anti-serum to this protein positively stained most of the cultured cells from the bovine retina indicative of their glial origin. Vimentin is an intermediate filament found in many cells, with Mueller cells being particularly rich in vimentin. 

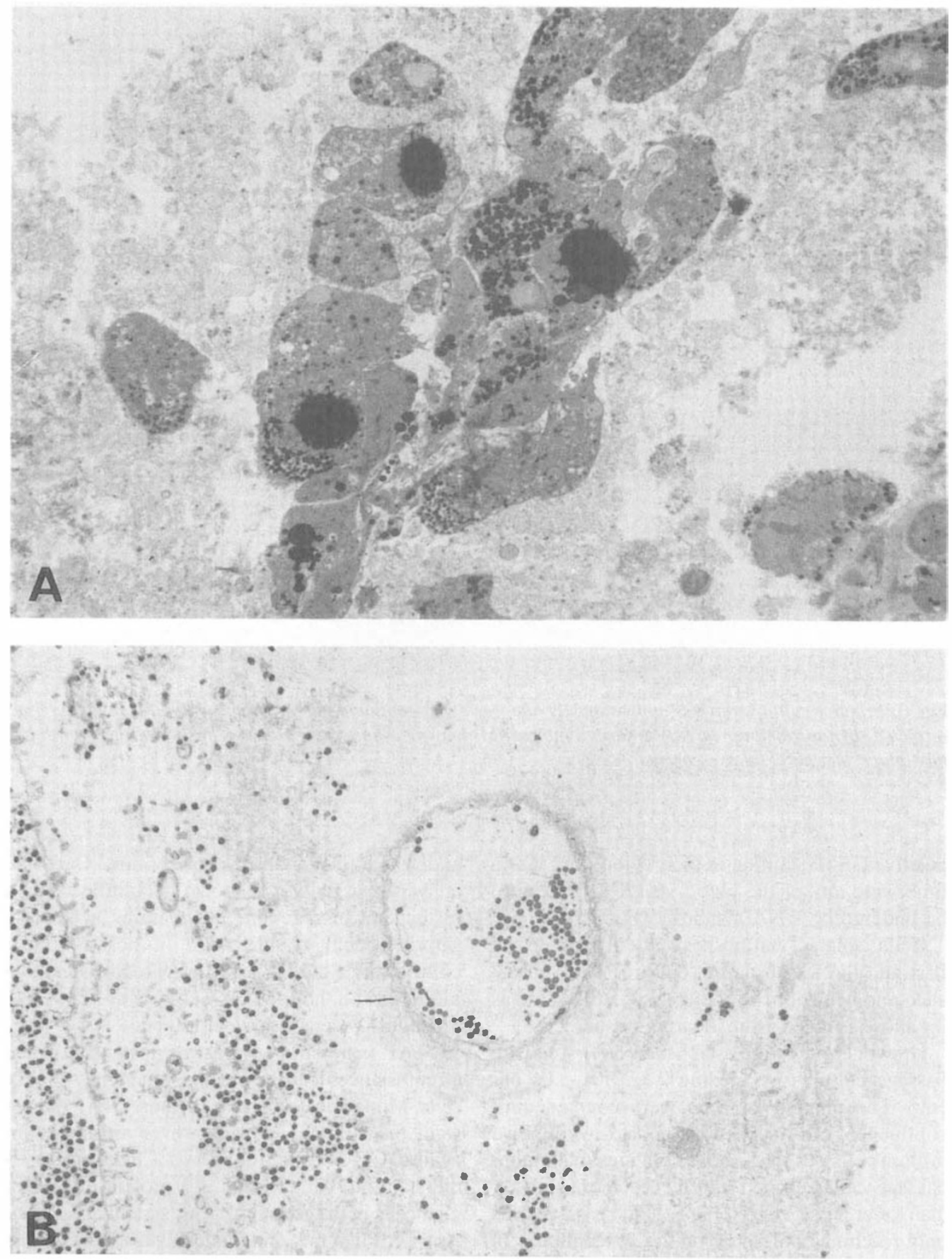

Fig. 4. (A) Autoradiograph $\left({ }^{3} \mathrm{H}\right.$-thymidine $)$ of floating bovine retinal tissue after 15 days in culture. Incorporation of thymidine into large round cells (Mueller cells). $\times 450$.

(B) Segment of tissue containing blood vessels, no ${ }^{3} \mathrm{H}$-thymidine is associated with these vessels. $\times 180$. 


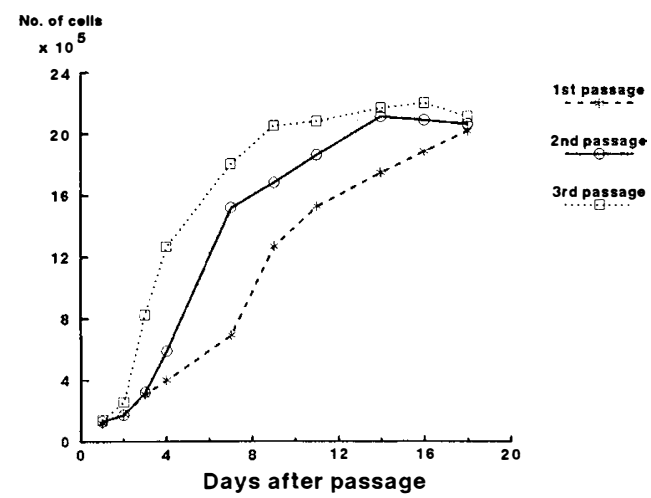

Fig. 5. Growth curves of bovine retinal glia in culture from first to third passage. First passage cells reach confluence in 16 days whereas third passage cells take only 8 days.

All cells cultured from the bovine retina were found to stain with antibody to vimentin. Astrocytes cultured from the brain have also been shown to stain with an antibodies to vimentin. ${ }^{28}$

Contaminating cells were not present in the culture as antibodies to keratins to demonstrate retinal pigment epithelial cells did not stain the cultured cells. Antibodies against desmin and
factor-VIII were used to determine if endothelial cells from the blood vessels were present. No cells stained with either antibody and although contamination by pericytes cannot be discounted in the cultures from floating tissue, the autoradiography studies suggested these were unlikely to be present as there was no DNA synthesis associated with blood vessels (Table I).

One of the possible contaminants from the neural retina is the neuronal cells themselves, however these do not readily survive in culture, Adler et $\mathrm{al}^{4}$ in cultures from chick embryos found that when fetal calf serum was included in the media by the sixth day none of the neuronal cells were still capable of proliferation and there were not many neuronal cells the culture being predominated by flat cells, which were negative for tetanus toxin, a neuronal marker.

\section{Identification of Retinal Glial Cells}

To be able to identify the cells grown in culture, a marker specific for glial cells would be an advantage, for glial cells a variety of factors have been used, including glial fibrillary acidic protein (GFAP), an intermediate filament, S-100, a protein and two enzymes, carbonic anhydrase and glutamine synthetase.

TABLE I Immunohistochemical staining of bovine cells

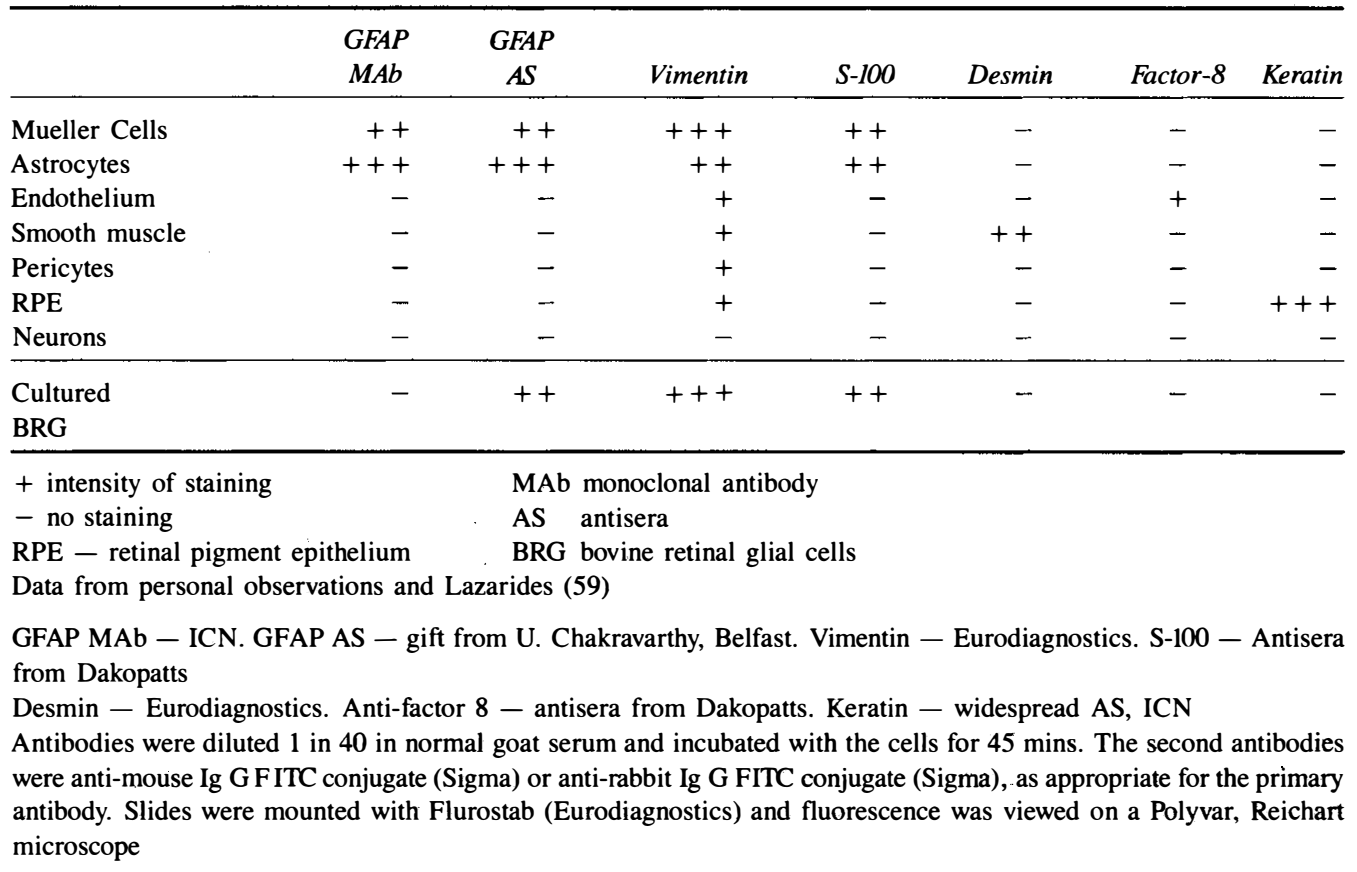




\section{Carbonic Anhydrase}

Carbonic anhydrase catalyses the hydration of $\mathrm{CO}_{2}$, several isomers of the enzyme exist, carbonic anhydrase II being present in Mueller cells. In the embryonic retina, carbonic anhydrase is present in all cells of the undifferentiated retina but as development occurs it becomes localised to the Mueller cells. ${ }^{29}$ In Mueller cells, carbonic anhydrase II is located in the cytoplasm and the membranes. Its function is probably to convert $\mathrm{CO}_{2}$, produced by the neurons, to bicarbonate and hydrogen ions for use by glial cells to maintain an optimal electrolyte environment for neural activity. Although this isoenzyme is located at several sites within the eye, in the retina, carbonic anhydrase II is found only in the Mueller cells, in the pigment epithelia and in erythrocytes. ${ }^{30}$ Retinal pigment epithelial cells can be identified by staining for keratin, an epithelial cell marker, to distinguish them from Mueller cells. To assay for activity either a histochemical reaction or an antibody can be employed. Neither of these are entirely satisfactory because the histochemical reaction is inconsistent and as yet, a monoclonal antibody or an antiserum is not commercially available. However several research laboratories have produced their own, for example, Sarthy using an anti-carbonic anhydrase II, developed in house, showed that $90 \%$ of the cells in a culture of Mueller cells from a rat retina exhibited carbonic anhydrase activity. ${ }^{8}$

\section{Glutamine Synthetase}

Glutamine synthetase (EC 6.3.1.2) catalyses the amidation of glutamate to glutamine, an essential precursor of several biosynthetic pathways. In the nervous system it is involved in the recycling of putative amino acid neurotransmitter molecules such as glutamate and GABA released by physiologically active neurons. ${ }^{31,32}$ Initially glutamine synthetase is not present in the embryonic retina, only being expressed after cell-to-cell contacts become established. Also maturation of the adrenal gland with the consequent release of corticosteroids is required. Glutamine synthetase is only expressed by the Mueller cells of the retina ${ }^{33}$ and therefore can be used as a specific marker. Low levels of glutamine synthetase can be determined after induction with hydrocortisone, with increased amounts when glia-neuron interactions are present. Therefore in cultures of glial cells detection is difficult, activity can be measured in post-confluent cultures after induction with hydrocortisone although levels are low. Burke and Foster ${ }^{9}$ in rabbit cultures were not able to reproducibly determine glutamine synthetase activity, while Sarthy ${ }^{8}$ in cultures of glial cells from the rat retina using an antiserum to glutamine synthetase was able to demonstrate that $82 \%$ of the cells in culture were positively stained.

\section{Glial Fibrillary Acidic Protein (GFAP)}

GFAP is an intermediate filament, found in astrocytes. Mueller cells, in certain circumstances, also show the presence of GFAP. We have shown that in normal bovine retina Mueller cells expressed GFAP (unpublished observation) whereas in the human ${ }^{34}$ and rat $^{35,36,37}$ retinae it was localised by antibodies only after injury. The expression of GFAP in cultured cells is variable, primary cultures of astrocytes have been shown to be positive for GFAP but on passage, cultures gradually lost their ability to show positive staining for GFAP and by the fifth passage no cell was positive for GFAP although all cells expressed vimentin. ${ }^{28}$

Duffey $^{38}$ found that the distribution of GFAP within the cell was dependent on the state of the cell, those cells that underwent morphological differentiation had a GFAP pattern that became more peripheral whereas undifferentiated cells retained a perinuclear GFAP distribution.

The work of Bjorklund and Dahl ${ }^{39}$ suggested that GFAP may be a family of closely related but not identical polypeptides. They used antisera and monoclonal antibodies against GFAP and showed that with the antiserum in the mouse and the rat, staining was seen in normal iris fibres, reactive cells in disturbed irides, lens epithelial cells, normal Mueller glia and those in damaged retina and retinal astrocytes. The monoclonal GFAP, however, only stained retinal astrocytes. Hatfield et $\mathrm{al}^{40}$ also showed GFAP immunoreactivity in lens epithelial cells. Schwann cells had been shown to stain for GFAP and it may be the unmyelinated nerve fibres in the iris which were showing GFAP reactivity.

\section{S-100 Protein}

$\mathrm{S}-100$ is a protein that was first isolated from the brain, immunocytochemical studies have shown 
it to be localised in brain astrocytes. ${ }^{41}$ In the retinae of the rat, guinea pig, hamster ${ }^{42}$ and human $^{43}$ S-100 has been found, using antibodies, to be localised to the Mueller cells. Although Malner et al ${ }^{44}$ could not localise S-100 in the Mueller cells of the human retina, this could be a result of the different techniques used to prepare the tissue for staining. This protein may be a marker for Mueller cells.

Individually these markers may not be sufficient to identify conclusively Mueller cells in culture but in combination, they can be used to ascertain if the cells are Mueller cells.

\section{Uses of Cultured Glial Cells}

There have been several uses of cultured glial cells including determination of the events which take place in embryonic development of the retina, study of cellular interactions, investigations of cell migration and as a support for other cell types in culture.

Linser and Perkins ${ }^{45}$ worked with cultures derived from dissociation of embryonic retina to investigate the capacity of retinoblast cells to mature into definitive Mueller cells. They used two markers to follow the maturation, carbonic anhydrase and glutamine synthetase. Carbonic anhydrase was expressed early in the development of the retina, initially it was present in all retinoblasts and then became restricted to the Mueller cells. Glutamine synthetase was induced in Mueller cells late in development in response to the maturation of the adrenal cortex and resultant elevation of systemic corticosteroids and to the formation of contact interactions with neuronal cells. Carbonic anhydrase but not glutamine synthetase was expressed when the interaction of neurons with glia was prevented, suggesting that for complete maturation of Mueller cells glia-neuron connections are necessary.

Burke $^{46}$ established glial cultures from the avascular rabbit retina to determine the influence of cell-to-cell contacts on DNA synthesis and compared the findings with those from rabbit dermal fibroblasts. When glia and fibroblasts were settled at the same cell number in culture, the glia formed more contacts with each other than fibroblasts. For glia, the labelling rate with ${ }^{3} \mathrm{H}$-thymidine increased with the number of cell-cell contacts, whereas fibroblasts with three or more cell contacts had a depressed labelling.
The factor(s) which caused this difference in behaviour is, as yet, unknown.

Burke and Foster ${ }^{47}$ also investigated the effect on DNA synthesis of culturing glia with other cell types. Co-cultures of retinal pigment epithelial and retinal glia showed a higher labelling rate than expected from cultures of each type alone. There was increased DNA synthesis in both cell types whereas co-culture of glia with dermal fibroblasts only increased the synthesis of fibroblasts. The increase in DNA synthesis of retinal pigment epithelial and fibroblasts induced by glial cells was shown to be due to factors secreted by the cells whereas for glial cells, contact of cells was necessary to stimulate synthesis. It is possible, however, that the interactions between the cells may influence their behaviour to humoral factors. These experiments were carried out to determine some of the factors which could influence divisional behaviour in pathological conditions like proliferative vitreoretinopathy.

Another facet of proliferative vitreoretinopathy is the migration of cells from their normal site to the retinal surfaces. To investigate the migratory behaviour of glial cells Harvey, Roberge and Hjelmeland ${ }^{48}$ have tested cells from the rat retina. They found platelet-derived growth factor was a chemoattractant for glia but epidermal growth factor, transforming growth factor-B, endothelial cell growth factors, hepatoma-derived growth factor and retinaderived growth factor did not cause their migration. Rat glia were found to migrate to vitreous and a retinal homogenate but not to pigment epithelium and conditioned medium from pigment epithelial cells. Surprisingly, although platelet-derived growth factor had profound effects on cell migration, it did not stimulate glial cell division. ${ }^{49}$

Peters et $\mathrm{al}^{50}$ studied whether the injection of cultured Mueller glial cells from the rabbit into the rabbit vitreous caused the formation of epiretinal membranes. Membranes did develop on injection of 750,000 glial cells and these were unpigmented and caused detachment of the medullary ray in some eyes. At lower injection numbers there was membrane formation and occasionally focal traction. Initially the membranes were predominantly cellular, with fibroblastic-like cells at the periphery and more epithelioid ones near the centre. Later extra- 
cellular matrix was present and proliferating cells were seen at the periphery of the tissue, the number of dividing cells decreasing with time.

$\mathrm{Li}$ and Sheffield ${ }^{51}$ have employed glial cells isolated from neural retina as support cells for the growth of neuronal cells. The neuronal cells adhered to the glial cells in a random fashion forming clusters or patches in which the cells were loosely dispersed on the glial cells. Three to four days after plating, a network consisting of axon-like fibres and single or clustered neural retina cells formed on the glial cell surface, these fibres originated from the neurons.

We have been studying the cells grown from the bovine retina in a single, intact cell contraction assay. In this assay, cultured cells were exposed to $\mathrm{Na}_{2}$ ATP for 60 mins and the resulting contraction was followed under phase contrast microscopy using a time-lapse system (Olympus). Drawings of the film were made on a film reader (Jena) at 0, 10 and 60 minutes and the area of each cell was computed using an image analyser (MOP videoplan, Kontron). It was found that glial cells contract with a dose optimum of $15 \mathrm{mM}$ ATP, which is the same as rabbit tenon's fibroblasts. ${ }^{52}$ At this dose, there was a $75 \%$ reduction from the original area of the cells (Fig 6). On removal of the ATP, the cells were able to relax towards their original area and on addition of further ATP could recontract. This cycle of contraction and relaxation could be repeated at least four times (Fig 6). This assay should enable us to have a better understanding of which cells may be involved in



Fig. 6. The change in surface area of cultured bovine glial cells when exposed to $15 \mathrm{mM}$ ATP. The graph shows 4 periods of contraction (arrowheads) and subsequent relaxation. (Mean values with SEMs). the contractile process in tractional retinal detachment. Possible inhibitors of the contractile process can be assessed by this system, which is similar to an organ bath muscle preparation but employing single cells.

The original work on contraction of cultured cells by ATP was on cells that had been treated with either detergent or glycerine to produce cytoskeletons..$^{53,54,55,56}$ Pretreatment was thought to be necessary for contraction to occur because the intact cells had strong adhesion to the rigid substrate on which they were grown. In such circumstances only isometric forces could be expressed. When loosened from the substrate the permeabilised cells were free to move so that isotonic contraction could then be measured. ${ }^{56} \mathrm{~A}$ comparison of the ability of intact and detergent treated cells, grown from epiretinal membranes, to contract on addition of ATP showed there was no difference between the two systems. ${ }^{57}$ Intact cultured fibroblasts have also been shown to contract. ${ }^{52}$ There are advantages in working with intact cells and not cytoskeletons, one being that the outline of the cells are clearer making assessment of the reduction in cell area easier. The cytoskeletal elements necessary for contraction cannot be eluted and the treatment required to produce cytoskeletons has been found to cause some loss of cell function. ${ }^{54}$ The contraction resulting from addition of ATP can be easily reversed and repeated with intact cells whereas cytoskeletons particularly if produced by glycerine treatment tend to break up during contraction making relaxation and assessment of repeatability of the response impossible. ${ }^{53}$

\section{Conclusions}

Several methods are available for the culture of glial cells from the retina, all the techniques result in cultures which are dominated by Mueller cells. The problems associated with the culture of glial cells from the retina are (a) the complexity of the isolation procedure, (b) preventing contamination of cultures by other cell types and (c) characterisation of the cultured cells. We have developed a simpler method for growing glial in culture from the vascular bovine retina. This procedure has the advantage that large numbers of cultures can be prepared easily and quickly from a vascular retina. For experiments in which many cells are required primary and low passage number cultures can still be employed with a rapid 
culture procedure, lessening problems with alterations in cell characteristics on passaging. Work is in progress to develop these methods for culture of glial cells from the human retina. To date there is only one report of human glial cells being cultured and that is by a modification of the Roberge technique ${ }^{58}$ with all the inherent difficulties we have previously discussed.

Cultures of glial cells have already been used in several different types of studies and with the development of simpler techniques to culture the cells, particularly if human glial cells can be grown by these methods, their use is likely to be more extensive. Cultures allow easier investigation of the role of cells in normal and pathological situations, in which the events occurring in vivo are complex. By first employing cultures of individual cell types we can begin to understand the influence of other factors and cellular interactions on the behaviour of cells. It is important therefore to continue with the development of glial cultures, to improve the conditions for growth and to find a definitive marker for these cultured cells.

This work was supported by grants from the Wellcome Trust (No. 15911/1.5/DG/AE/JW), TFC Frost Charity, Fight For Sight and the RNIB.

\section{References}

' Varon SS and Somjen GG. Neuron-glia interactions. Neurosci Res Prog Bull 1979; 17: 1-242.

${ }^{2}$ Hyden H. Quantitative assay of compounds in isolated fresh nerve cells and glial cells from control and stimulated animals. Nature 1959; 184: 433-5.

${ }^{3}$ Walker AG, Chapman J, Bruce CB, Rumsby MG. Immunocytochemical characterisation of cell cultures grown from dissociated 1-2-day post-natal rat cerebral tissue. A developmental study. $J$ Neuroimmunol 1984/5; 7: 1-20.

${ }^{4}$ Adler R, Magistretti PJ, Hyndman AG, Shoemaker WJ. Purification and cytochemical identification of neuronal and non-neuronal cells in chick embryo retina cultures. Dev Neurosci 1982; 5: 27-39.

${ }^{5}$ Sarthy PV and Lam DMK. Biochemical studies of isolated glial (Mueller) cells from the turtle retina. J Cell Biol 1978; 78: 675-84.

${ }^{6}$ Trachtenberg MC and Packey DJ. Rapid isolation of mammalian Mueller cells. Brain Res 1983; 261: 43-52.
${ }^{7}$ Roberge FG, Caspi RR, Chan C, Kuwabara T, Nussenblatt RB. Long term culture of Mueller cells from adult rats in the presence of activated lymphocytes/monocytes products. Curr Eye Res 1985; 4: 975-82.

${ }^{8}$ Sarthy PV. Establishment of Mueller cell cultures from adult rat retina. Brain Res 1985; 337: $138-41$.

${ }^{9}$ Burke JM and Foster SJ. Culture of rabbit retinal glial cells: methods and cellular origin of explant outgrowth. Curr Eye Res 1984; 3: 1169-74.

${ }^{10}$ Hogan MJ, Alvaredo IA, Weddell J. Retina In Histology of the human eye. An Atlas and textbook. Philadelphia: W B Saunders Co 1971: 393-522.

"Johnson NF. Retinal glycogen content during ischaemia. Graefe's Arch Clin Exp Ophthalmol 1977; 203: 271-82.

${ }^{12}$ Fine BS and Yanoff M. Retina In Ocular Histology. A text and atlas. New York: Harper and Row 1972: 47-107.

${ }^{13}$ Watanabe $\mathrm{T}$ and Raff MC. Retinal astrocytes are immigrants from the optic nerve. Nature 1988; 322: 834-7.

${ }^{14}$ Kuwabara $\mathrm{T}$ and Cogan DG. Retinal glycogen. Arch Ophthalmol 1961; 66: 680-8.

${ }^{15}$ Wolter JR. The astroglia of the human retina and other glial elements of the retina under normal and pathologic conditions. Am J Ophthalmol 1955; 40: 88-99.

${ }^{16}$ Ogden TE. Nerve fibre layer astrocytes of the primate retina: morphology, distribution and density. Invest Ophthalmol Vis Sci 1978; 17: 499-510.

${ }^{17}$ Wolter JR. Perivascular glia of the blood vessels of the human retina. Am J Ophthalmol 1957; 44: 766-73.

${ }^{18}$ Dixon RG and Eng LF. Glial fibrillary acidic protein in the retina of the paraffin-embedded tissue. J Comp Neurol 1981; 195: 305-21.

${ }^{19}$ Drager UC, Edwards DL, Barnstable CJ. Antibodies against filamentous components in discrete cell types of the mouse retina. $J$ Neurosci 1984; 4: 2025-42.

${ }^{20}$ Reichenbach A. Quantitative and qualitative morphology of rabbit retinal glia. A light microscopical study on cells both in situ and isolated by papaine. J Hirnforsch 1987; 2: 213-20.

${ }^{21}$ Schnitzer J. Retinal astrocytes: their restriction to vascularised parts of the mammalian retina. Neurosci Lett 1987; 78: 29-34.

${ }^{22}$ Reichenbach A and Wohlrab F. Quantitative properties of Mueller cells in rabbit retina as revealed by histochemical demonstration of NADH-diaphorase activity. Graefe's Arch Clin Exp Ophthalmol 1983; 220: 81-3. 
${ }^{23}$ Magalhaes MM. Functional cytoarchitecture of the retina Mueller cell. In Yamada and Mishima eds. The structure of the eye III 1976: 333-40.

${ }^{24}$ Johnson NF. Effect of acute ischaemia on the structure of the rabbit retina. Preliminary Observations. Trans Ophthalmol Soc UK 1974; 94: 394-405.

${ }^{25}$ Chan CC, Rozenszajn LA, Nussenblatt RB, Mullenberg-Coulombre C, Hsu SM, Palestine AG, Lando Z, BenEzra D. Monoclonal antibody to Mueller cells of the retina. Invest Ophthalmol Vis Sci 1984; 25: 1007-12.

${ }^{26}$ Cross SAM. Ultrastructural localisation of carbonic anhydrase in rat stomach parietal cells. Histochemie 1970; 22: 219-25.

${ }^{27}$ Chakravarthy U, McCormick D, Maguire CJF, Archer DB. An in vitro study of irradiated vitreoretinal membranes. Eye 1987; 1: 126-35.

${ }^{28}$ Osborn M. Ludwig-Festl M, Weber K, Bignami A, Dahl D, Bayreuther K. Expression of glial and vimentin type intermediate filaments in cultures derived from human glial material. Differentiation 1981; 19: 161-7.

${ }^{29}$ Linser P and Moscona AA. Carbonic anhydrase C in the neural retina: Transition from generalised to glia-specific cell localisation during embryonic development. Proc Natl Acad Sci USA 1981; 78: 7190-4

${ }^{30}$ Wistrand PJ, Schenholm M, Lonnerholm G. Carbonic anhydrase isoenzymes CA I and CA II in the human eye. Invest Ophthalmol Vis Sci 1986; 27: 419-28.

${ }^{31}$ Hamberger A, Chiang GH, Nylen ES, Schiff SW, Cotman CW. Glutamate as a CNS transmitter. I Evaluation of glucose and glutamine as precursors for the synthesis of preferentially released glutamate. Brain Res 1979; 168: 513-30.

32 Taipa $\mathbf{R}$. In Mora $\mathbf{J}$ and Palacios $\mathbf{R}$ eds. Glutamine: metabolism, enzymology and regulation. New York: Academic Press 1980: 285-98.

${ }^{33}$ Moscona AA, Linser P, Mayerson P, Moscona M. Regulatory aspects of the induction of glutamine synthetase in embryonic neural retina. In Mora $\mathbf{J}$ and Palacios $\mathrm{R}$ eds. Glutamine: metabolism, enzymology and regulation. New York: Academic Press 1980: 299-313.

${ }^{34}$ O'Dowd DK and Eng LF. Immunocytochemical localisation of glial fibrillary acidic (GFA) protein in the Mueller cell of the human retina. Soc Neurosci Abstr. 1979; 5: 431.

${ }^{35}$ Bignami A, Dahl D. The radial glia of Mueller cells in the retina and their response to in jury an immunofluorescence study with antibodies to the glial fibrillary acidic protein. Exp Eye Res 1979; 28: 63-9.
${ }^{36}$ Eisenfeld AJ, Bunt-Milam AH, Sarthy PV. Mueller cell expression of glial fibrillary acidic protein after genetic and experimental photoreceptor degeneration in the rat retina. Invest Ophthalmol Vis Sci 1984; 25: 1321-8.

${ }^{37}$ Shaw G and Weber $K$. The structure and development of the rat retina - an immunofluorescence microscopical study using antibodies specific of intermediate filament proteins. Europ J Cell Biol 1983; 30: 219-32.

${ }^{38}$ Duffey PE. Glial fibrillary acidic protein and induced differentiation of glia in vitro. $J$ Neurol Sci 1982; 53: 443-60.

${ }^{39}$ Bjorklund B and Dahl D. Glial fibrillary acidic protein (GFAP)-like immunoreactivity in the rodent eye. J Neuroimmunol 1985; 8: 331-45.

${ }^{40}$ Hatfield JS, Skoff RP, Maisel H, Eng LF. Glial fibrillary acidic protein is localised in the lens epithelium. J Cell Biol 1984; 98: 1895-8.

${ }^{41}$ Moyes, BE, Lim SU, Lee V, Sung SC. Immunohistochemical co-localisation of $\mathrm{S}-100 \mathrm{~b}$ and the glial fibrillary acidic protein in rat brain. Neurosci 1986; 17: 857-65.

${ }^{42}$ Terenghi G, Cocchia D, Michetti F, Diani AR, Peterson T, Cole DF, Bloom SR, Polak JM. Localisation of S-100 protein in Mueller cells of the retina -1 . Light microscopical immunochemistry. Invest Ophthalmol Vis Sci 1983; 24: 976-80.

${ }^{43}$ Das A, Pansky B, Budd GC, Kollaritis CR. Immunocytochemistry of mouse and human retina with antisera to insulin and S-100 protein. Curr Eye Res 1984; 3: 1397-403.

${ }^{44}$ Molnar ML, Stefansson K, Molnar GK, Tripathi $\mathrm{RC}$, Marton LS. Species variations in distribution of S-100 in retina. Invest Ophthalmol Vis Sci 1985; 26: 283-8.

${ }^{45}$ Linser PJ and Perkins MS. Regulatory aspects of the in vitro development of retinal Mueller glial cells. Cell Differentiation 1987; 20: 189-96.

${ }^{46}$ Burke JM. Cell-cell contact promotes DNA synthesis in retinal glia but not in fibroblasts. Exp Cell Res 1983; 146: 204-6.

${ }^{47}$ Burke JM and Foster SJ. Induction of DNA synthesis by co-culture of retinal glia and pigment epithelium. Invest Ophthalmol Vis Sci 1985; 26: 636-42.

${ }^{48}$ Harvey AK, Roberge F, Hjelmeland LM. Chemotaxis of rat retinal glia to growth factors found in repairing wounds. Invest Ophthalmol Vis Sci 1987; 28: 1092-9.

${ }^{49}$ Burke JM. Cultured retinal glial cells are insensitive to platelet-derived growth factor. Exp Eye Res 1982; 35: 663-9. 
${ }^{50}$ Peters MA, Burke JM, Clowry M, Abrams GW, Williams GA. Development of traction retinal detachments following intravitreal injections of retinal Mueller and pigment epithelial cells. Graefe's Arch Clin Exp Ophthalmol 1986; 224: 554-63.

${ }^{51} \mathrm{Li} \mathrm{H}-\mathrm{P}$ and Sheffield JB. Retinal flat cells are substrates that facilitates retinal neuron growth and fibre formation. Invest Ophthalmol Vis Sci 1986; 27: 296-306.

52 Joseph JP, Grierson I, Hitchings RA. Exogenous ATP causes contraction of intact fibroblasts in vitro. Exp Cell Res 1988; 176: 1-12.

${ }^{53}$ Norberg B. Amoebiod movements and cytoplasmic fragmentation of glycerinated leukocytes induced by ATP. Exp Cell Res 1970; 59: 11-21.

${ }^{54} \mathrm{Hsu}$ LS and Becker EL. Volume decrease of glycerinated polymorphonuclear leukocytes induced by ATP and $\mathrm{Ca}^{2+} 1$. Resemblances to actomyosin contraction. Exp Cell Res 1975; 91 : 469-73.
${ }^{55}$ Masuda H, Owaribe K, Hatano S. Contraction of triton-treated culture cells. A calcium-sensitive contractile model. Exp Cell Res 1983; 143: 79-90.

${ }^{56}$ Hitchins CA, Yonug JD, Day J, Grierson I. Shape changes produced in detergent extracted bovine retinal pigment epithelium when exposed to ATP. A comparison with fibroblasts and smooth muscle cells. Acta Ophthalmol 1988; 66: 38-43.

${ }^{57}$ Jiang DY, Hiscott PS, Grierson I, McLeod D. Growth and contractility of cells from fibrocellular epiretinal membranes in primary tissue culture. Br J Ophthalmol 1988; 72: 116-26.

${ }^{58}$ Hjelmeland LM, Harvey AK, Hohman TC, Juan Ede. Primary and chemotactic responses of human retinal glia. Invest Ophthalmol Vis Sci Suppl 1987; 28: 208.

${ }^{59}$ Lazarides E. Intermediate filaments: a chemically heterogeneous, developmentally regulated class of proteins. Ann Rev Biochem 1982; 51: 219-50. 